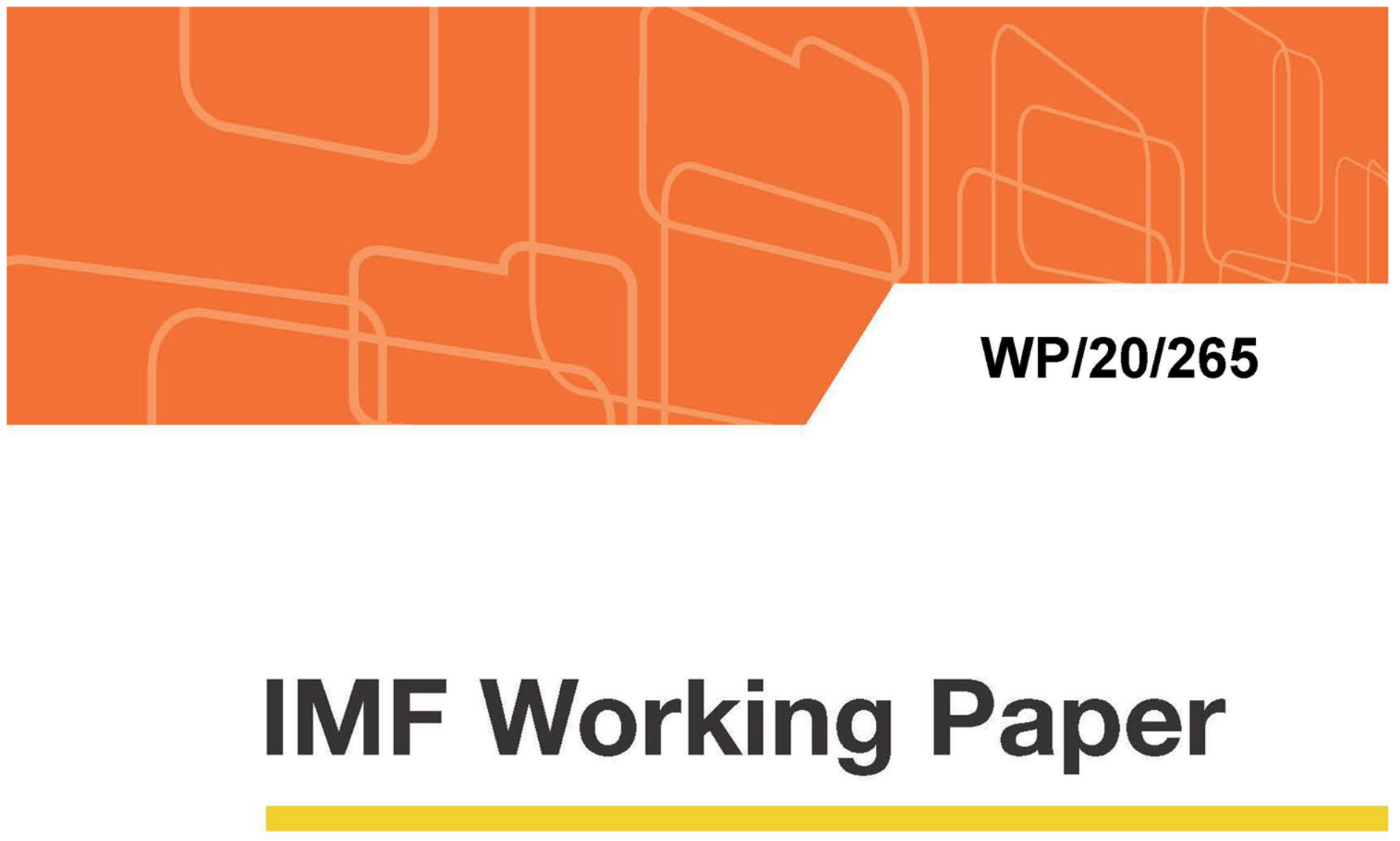

\title{
Incomplete Financial Markets and the Booming Housing Sector in China
}

\author{
by Tamim Bayoumi and Yunhui Zhao
}

IMF Working Papers describe research in progress by the author(s) and are published to elicit comments and to encourage debate. The views expressed in IMF Working Papers are those of the author(s) and do not necessarily represent the views of the IMF, its Executive Board, or IMF management. 


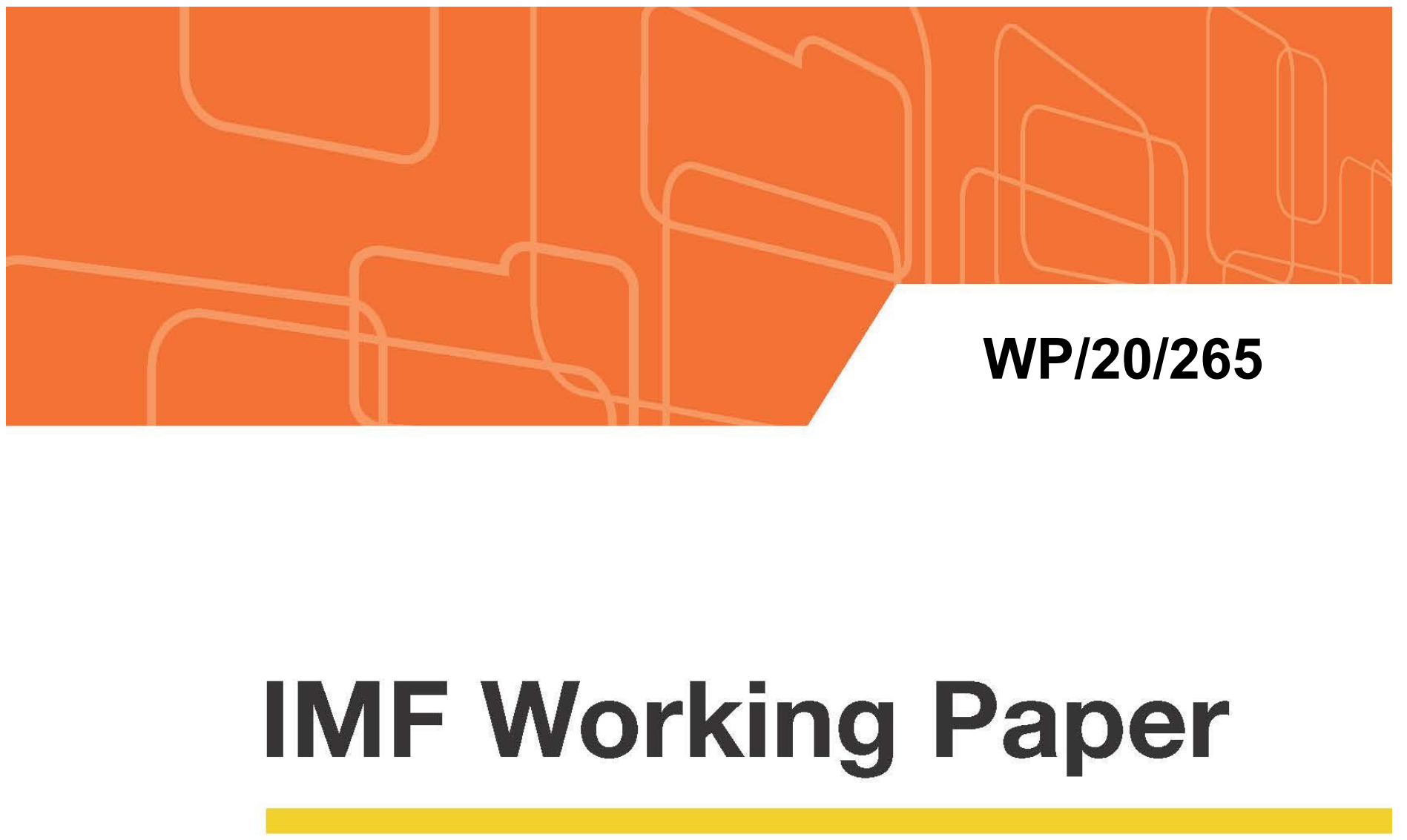

\section{Incomplete Financial Markets and the Booming Housing Sector in China}

by Tamim Bayoumi and Yunhui Zhao

IMF Working Papers describe research in progress by the author(s) and are published to elicit comments and to encourage debate. The views expressed in IMF Working Papers are those of the author(s) and do not necessarily represent the views of the IMF, its Executive Board, or IMF management. 


\title{
IMF Working Paper
}

Strategy, Policy, and Review Department

\section{Incomplete Financial Markets and}

\section{the Booming Housing Sector in China}

\author{
Prepared by Tamim Bayoumi and Yunhui Zhao ${ }^{1}$ \\ Authorized for distribution by Tamim Bayoumi \\ December 2020
}

\begin{abstract}
IMF Working Papers describe research in progress by the author(s) and are published to elicit comments and to encourage debate. The views expressed in IMF Working Papers are those of the author(s) and do not necessarily represent the views of the IMF, its Executive Board, or IMF management.
\end{abstract}

\begin{abstract}
Housing is by far the most important asset in Chinese households' balance sheets. However, despite forceful and frequent government interventions, the rise in Chinese housing prices has not been contained as much as intended, a trend that has not been reversed by the COVID-19 shock. In this paper, we first provide some stylized facts and then a DSGE model (encompassing both demand and supply channels) to highlight the impact of a "slow-moving" structural vulnerability - financial market incompleteness - on China's housing prices. The model implies that to eradicate the root causes of the rising housing price, policymakers need to go beyond the housing market itself; instead, it would be desirable to deepen financial markets because these markets would help channel financial resources to productive sectors rather than to housing speculation. This is particularly important in the COVID era because without addressing this structural vulnerability, the higher household savings and the government stimulus may fuel the housing bubble and sow seeds for a future crisis. The paper can also shed light on the housing markets in other economies that face similar vulnerabilities.

JEL Classification Numbers: E00, G18, G28, R30

Keywords: Chinese housing, COVID-19, Financial market incompleteness, DSGE Authors' E-Mail Addresses: tamim.bayoumi@gmail.com; yzhao@imf.org

\footnotetext{
${ }^{1}$ We are grateful for the helpful discussions during the presentation to the China team (with Helge Berger, Fei Han, Kenneth Kang, and other team members); for the comments received during the formal review stage (from Katharina Bergant, Diego Alejandro Cerdeiro, Junghwan Mok, Cian Ruane) and at the surveillance meeting; and for the helpful discussions with Zhuo Chen (Tsinghua), Martin Cihak, Ding Ding, Jack Favilukis (UBC), Wei Guo, Dong He, Zhiguo He (Chicago), Zhongxia Jin, Petya Koeva Brooks, Ivo Krznar, Li Lin, Jianhai Lin, Yang Liu, Wojciech Maliszewski, Paul Mathieu, Alex Murray (Finance Canada), Xiaohui Sun, Rengming Xie, TengTeng Xu, Wentao Xiong (Harvard), Daria Zakharova, Fudong Zhang (Tsinghua), Tianxiao Zheng, and especially Chuqiao Bi and Tao Zha (Atlanta Fed). We also thank Tiana Wang for her research assistance.
} 


\section{Contents}

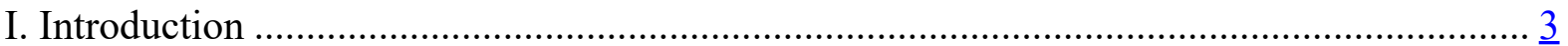

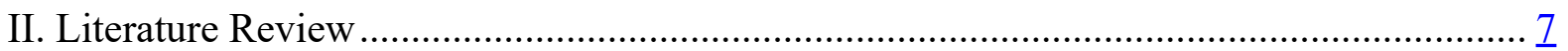

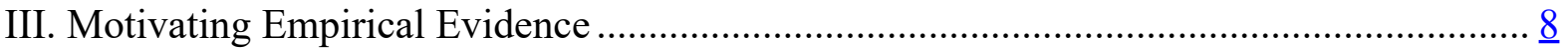

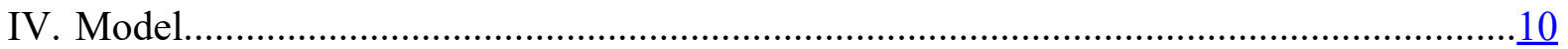

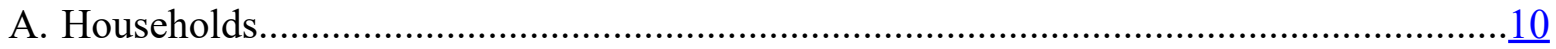

B. Real Estate Developer.................................................................................... 15

C. Production of Non-housing Consumption Goods....................................................18

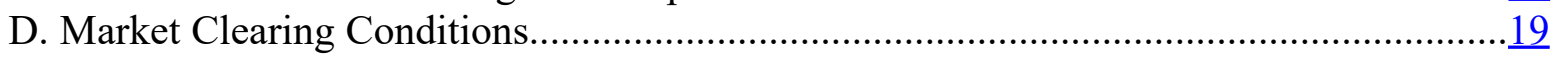

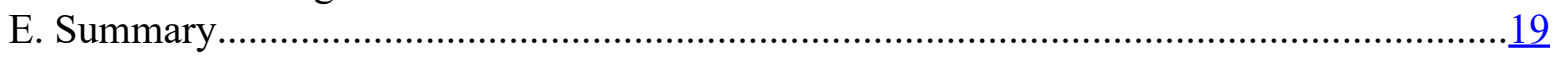

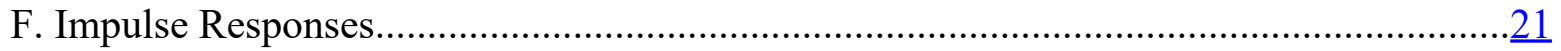

V. Conclusion and Policy Implications …………………............................................... 24

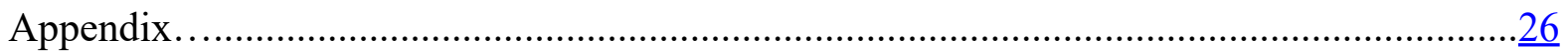

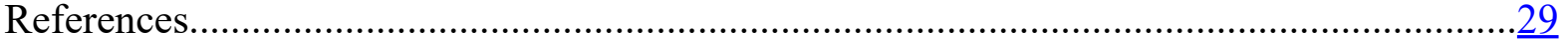

\section{Figures}

Figure 1. Composition of Households' Assets ……….......................................................

Figure 2. Residential House Price.........................................................................................

Figure 3. Household Saving Deposit and Stock Price Index .................................................... 9

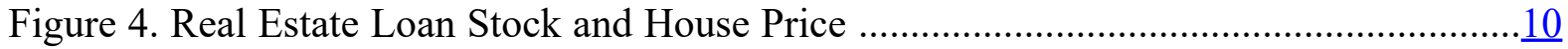

Figure 5. Impulse Response Functions with A More Incomplete Financial Market ...............23

\section{Tables}

Table 1. Structure of Chinese Financial Markets.................................................................... 


\section{Introduction}

Housing is by far the most important asset in households' balance sheets across the world, particularly in China, and high housing prices have been linked to a lower rate of consumption (Yang, Fan, and Zhao, 2018). As shown in Figure 1, housing accounts for 65.3 percent of Chinese households' assets, as opposed to 36.0 percent in the US. Hence, it is of vital importance to understand the driving forces for, and the implications of, high housing prices.

Figure 1. Composition of Households' Assets

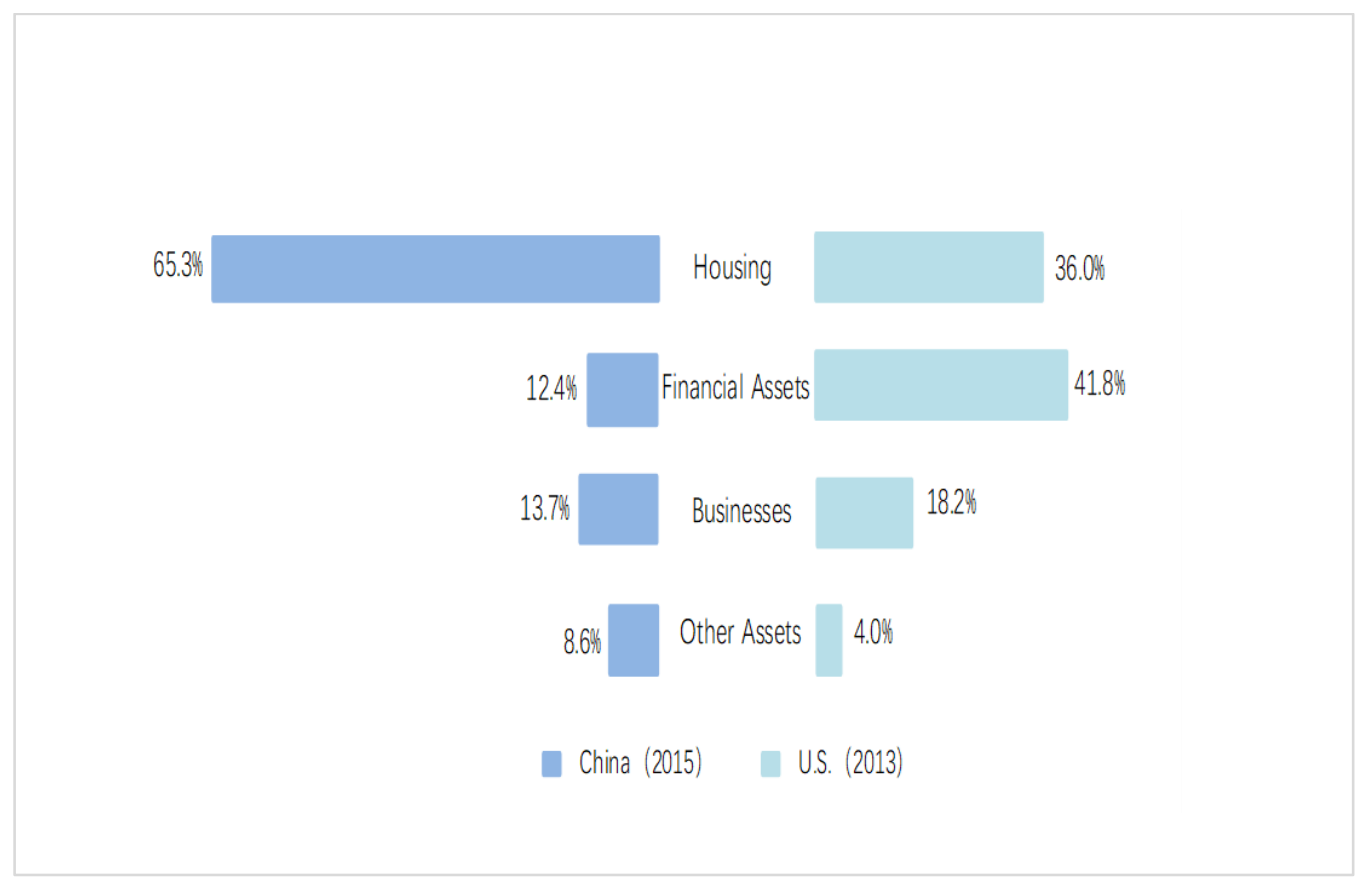

Source: Gan and others (2016).

Moreover, China's housing market and financial system have quite a few interesting aspects. First, despite forceful and frequent government interventions, the rising housing price has not been contained as much as intended. Ever since the housing market reform in 1998, house prices have been on a rising trend. More strikingly, this trend has not been reversed even by the unprecedented COVID-19 shock (Figure 2), despite severe disruptions to economic activities and employment. For example, in March 2020 when China was in the midst of the COVID crisis, 288 apartments in a Shenzhen neighborhood sold out online in less than eight minutes; and residential real estate investment in China now has exceeded that in the U.S. before the 2008 financial crisis (Wall Street Journal, July 17, 2020). ${ }^{2}$ In July 2020, China's average residential house price surpassed a landmark of 10,000 RMB/sq.m. for the first time. And despite the new regulation (issued on September 28, 2020) that new housing-related loans should not exceed 30 percent of total bank loans, housing prices continued to rise in October.

${ }^{2}$ The rising trend of the housing price in the US is also not reversed by the COVID-19, as discussed in Zhao (2020). 
In fact, the China Household Finance Survey (by Southwestern University of Finance and Economics) suggests that COVID-19 has encouraged speculative house purchases that the government has been trying to prevent. Lower consumption and higher saving in the COVID era raise housing demand largely amongst people who already own multiple properties (as more saving from the rich flows into the housing market, a trend that is reinforced as more saving from the poor flows into banks and decreases the mortgage rate further). As Professor Gan Li, an expert in Chinese household finance, puts it: "Speculative demand is on the rise because [people] view housing as a safer asset than the stock market or overseas assets... Because of the pandemic they're actually consuming less, and saving more. So they'll actually have more money available to invest. That will create an even larger housing problem."

\section{Figure 2. Residential House Price}

(Nominal, July 2017-October 2020)

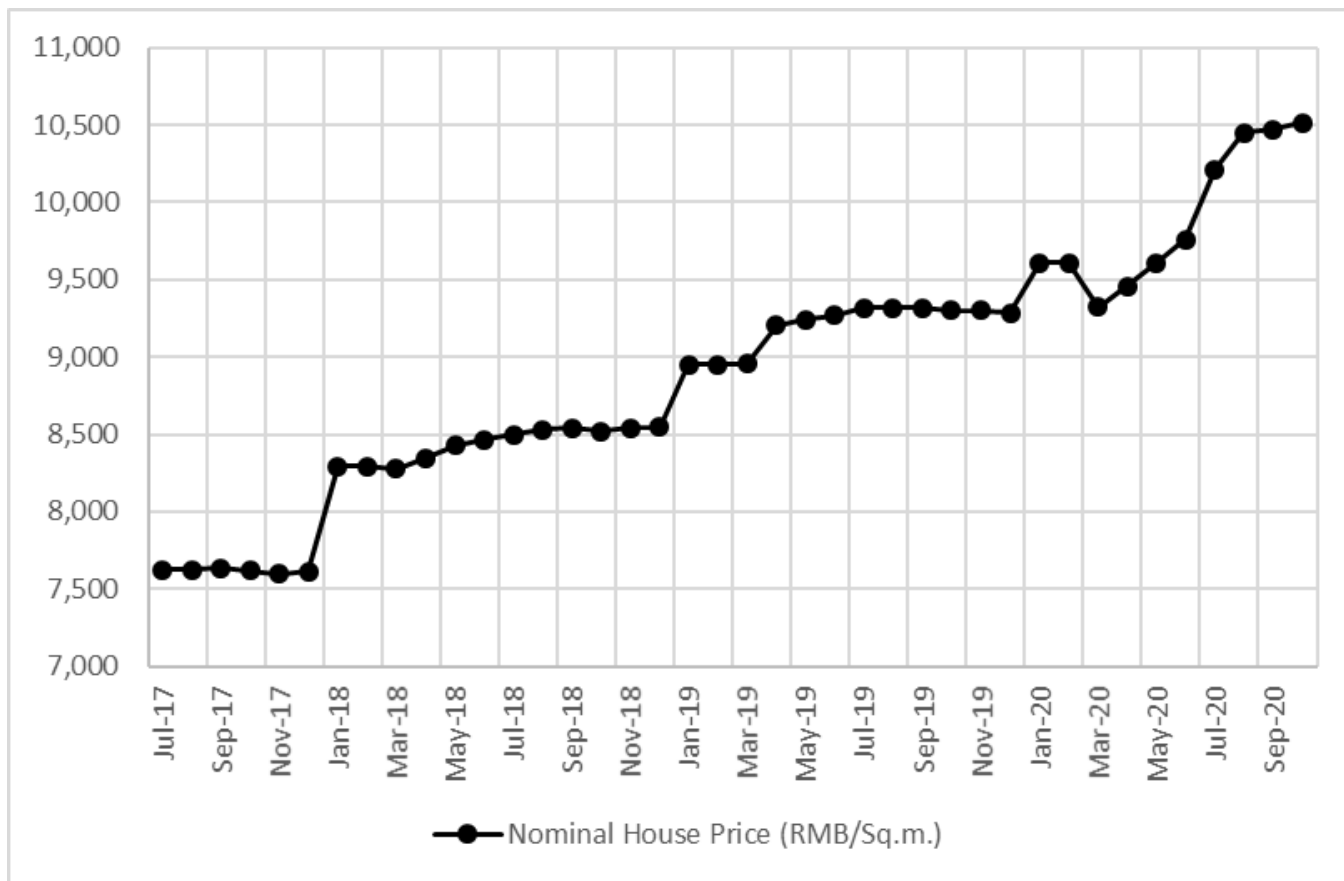

Source: CEIC; China Index Academy (Sep-Oct 2020); and author calculations.

Second, despite the well-known abundant household savings in China (see, e.g., Zhang and others, 2018), its small-and-medium enterprises (SMEs) have been facing chronic financing difficulties. The co-existence between abundant supply of funds and large, unmet demand for credit is in sharp contrast with the predictions of standard economic models.

Third, despite being the world's second largest economy, China's financial market is heavily bank-dominated. As shown in Table 1, the financing done through the so-called second-board stock market (China's counterpart to NASDAQ in the US) has been only about 1-2 percent of bank loans while the financing done through the small-and-medium board market has been only about 3-5 percent of bank loans. Even the seemingly emerging bond 
market is dominated by banks: more than 75 percent of corporate bonds are held by banks (as of end-2018). Moreover, China has widespread legal restrictions on "illegal fund-raising", with some high-profile cases involving capital punishment.

Table 1. Structure of Chinese Financial Markets

\begin{tabular}{|c|c|c|c|c|}
\hline Indicator (100 mil. RMB) & 2015 & 2016 & 2017 & 2018 Jan-Jul \\
\hline Social financing scale (accumulative) & 154,086 & 178,022 & 204,009 & 107,332 \\
\hline $\begin{array}{c}\text { Social financing scale: new RMB loan } \\
\text { (accumulative) }\end{array}$ & 112,693 & 124,372 & 138,432 & 100,506 \\
\hline $\begin{array}{c}\text { Growth enterprise market (i.e., } \\
\text { second-board market) }\end{array}$ & 139 & 212 & 115 & 131 \\
\hline As a percent of loan & $1.1 \%$ & $1.9 \%$ & $1.1 \%$ & $0.9 \%$ \\
\hline Small-and-medium board & 1,526 & 875 & 588 & 248 \\
\hline As a percent of loan & $4.1 \%$ & $5.5 \%$ & $3.5 \%$ & $2.3 \%$ \\
\hline
\end{tabular}

Source: Wind and author calculations.

Is there an underlying force that drives all these phenomena? What is the crucial element needed to make the government's attempts to slow the housing market expansion more integrated and more effective? Such questions are important because by treating the above phenomena in an isolated manner, policymakers may be simply treating the symptoms rather than trying to eradicate the root causes of the disease.

This paper provides a unified framework from the perspective of financial market incompleteness, which explains the above phenomena in an integrated way and sheds light on the desirable housing policies. ${ }^{3}$ The main contribution is to highlight the impact of the "slowmoving" structural factor (i.e., the financial market structure) on China's housing prices in a stylized DSGE model with heterogeneous households. The model can also be extended to quantitatively assess the impacts of financial market reforms, social security system reforms, etc., on housing prices and other key macrofinancial indicators. Two main channels are at work:

On the demand side of the housing market, we illustrate how the incomplete financial markets have fueled the housing demand: (1) For "rich households" who can afford the down payments for multiple houses, the lack of alternative profitable or "safe" investment opportunities (due to the incomplete financial markets) has resulted in a stream of "hot money" flowing to the housing market, pulling up housing demand and house prices and possibly widening the wealth inequality. (2) For "poor households", effectively the only investment opportunity is to deposit their savings in banks (again due to the incomplete financial markets). As a result, banks have unusually abundant financial resources, much higher than many other countries. This pushes down the interest rate to a very low level, which in turn leads to a high borrowing demand by other households to buy houses.

\footnotetext{
${ }^{3}$ Incomplete markets are markets where the number of Arrow-Debreu securities is less than that of states of nature (Arrow, 1964). This shortage of securities will likely restrict individuals from transferring the desired level of wealth among states. In the case of financial markets, market incompleteness practically means the available investment channels (for savers) or financing channels (for borrowers) are inadequate for savers/borrowers to optimally allocate resources over time.
} 
Two more features are helpful for further understanding the financial market incompleteness in China. First, even though stock market investment is still an option, anecdotal evidence and comments from some prominent economists (e.g., Wu Jinglian) suggest that compared with housing investment, stock market investment is deemed more risky (e.g., due to reportedly insider trading). This can also be seen by the fact that the current level of Shanghai Composite Index is still about one third below its peak in 2007 (Figure 3). ${ }^{4}$ Second, it is well-known that China has relatively strict restrictions on overseas investment. According to the latest rules, starting from February 1, 2019, anyone holding foreign exchange more than RMB 5 million can be convicted of illegal business operations and be sentenced to imprisonment for up to five years or criminal detention, in addition to a fine. ${ }^{5}$

On the supply side of the housing market, the aforementioned low interest rate also stimulates a high borrowing demand by real estate developers to build houses, pushing up the housing supply. Since the increase of housing supply is subject to local governments' limited land supply, ultimately the demand effect dominates the supply effect, resulting in higher housing price in equilibrium. The high housing price and the associated high profit in the real estate industry attract more workers (and/or more bank credit), thereby crowding out resources from other productive industries.

Our key policy implication is that even though the high housing price does not seem to be directly related to financial market structure, the eradication of the root causes of the problem may still require developing financial markets. This is particularly important in the COVID era because without addressing the structural vulnerability of financial market incompleteness, the higher household savings and the government stimulus may fuel the housing bubble and sow seeds for a future crisis. The paper also illustrates in detail the pros and cons of various institutional designs during China's transition from a planned economy to a market economy, and thus can help inform policymakers in other countries that may consider adopting the "China Model". Indeed, preliminary cross-country evidence based on machine learning techniques indicates that our findings extend to a broader set of countries. ${ }^{6}$

The rest of the paper is structured as follows. Section II reviews related papers that are not discussed elsewhere in the paper. Section III presents some empirical evidence that further motivates our study. Section IV lays out the model and the results. Section V concludes and discusses some policy implications. Some technical parts are presented in the appendices.

\footnotetext{
${ }^{4}$ We could extend our model to include the stock market; however, for the "rich" households who can afford the down payments for multiple houses, housing is still a preferred investment under reasonable parameterizations. Therefore, for simplicity we did not add this market.

${ }^{5}$ The source can be found here. In addition, China's overseas investment in 2018 fell 9.6 percent, as the Chinese government's crackdown on capital flight continued (South China Morning Post, September 13, 2019).

${ }^{6}$ The lively-updated supplementary materials are available here.
} 


\section{Literature Review}

Our paper is connected to the literature on the Chinese housing market and the Chinese economy more broadly. ${ }^{7}$ The first strand of literature studies the driving forces for China's high housing price, particularly focusing on the role of local governments in China. Gao, Liu, and Long (2019) find evidence that housing price hikes from 2000 to 2015 result from both an inadequate supply of residential land and a "strong and rising demand". In a counterfactual analysis, Du and Zhang (2015) suggest that the absence of property tax in big cities like Shanghai did not contribute significantly to the high housing prices. ${ }^{8}$ Mei, Cui, and Wu (2018) study the impact of local governments' high infrastructure investments, which push up land demand, land price, and housing price. Bai, Hsieh, and Song (2016) document the importance of land sales revenues to local governments. Relatedly, Bai and Qian (2010), Huang (2017), and Chen, He, and Liu (2020) highlight the use of local government financing vehicles to finance local investments. In addition, Xiong (2019) focuses particularly on the agency problem between the central and local governments, where the economic "tournament" among local governors motivates them to develop local economies at the cost of some myopic behaviors, such as overleverage through shadow banking. ${ }^{9}$

The second strand of literature focuses on the resource misallocation associated with China's real estate boom. For example, in an empirical analysis for 330 Chinese cities from 2000 to 2015, Chen and others (2017) find two channels via which the real estate shocks affect corporate investment: the speculation channel-rapidly rising commercial land prices induce manufacturing and service firms to buy more commercial land for speculative purposes, which reduces the investment and innovation in their core activities; and the crowding-out channelin response to rising land prices, banks grant more credit to land-holding firms, leaving less financing to other firms. In addition, using data from 1995 to 2010, Shi (2018) find empirical evidence that more productive Chinese firms reallocate capital to the booming real estate sector in China. The impacts of some other factors on housing price have also been explored, such as the social interactions (households' tendency to keep up with the home ownership status of their communities) by Minetti, Peng, and Jiang (2019), and the presence of high-speed railways by Rungskunroch, Yang, and Kaewunruen (2020).

The third strand of literature studies China's "ghost towns" and different housing market dynamics across different regions. A ghost town is a newly constructed but mostly empty urban district, usually belonging to small-to-medium cities and located in areas far away from the city centers (Shepard, 2015). ${ }^{10}$ While the housing prices in big Chinese cities have been on a

\footnotetext{
${ }^{7}$ Liu and Xiong (2018) review the historical development of China's real estate market.

${ }^{8}$ Chen and Wen (2017) finds that China's housing boom can be interpreted as a rational bubble emerging naturally from its economic transition.

${ }^{9}$ Chen, Ren, and Zha (2018) also study the rise of shadow banking activities in China, although their focus is not on the housing market per se.

${ }^{10}$ Based on data from 2001 to 2012, Glaeser and others (2017) document that China's housing vacancy rate rose sharply after 2009. And as of February 2019, one-fifth of China's urban housing stock had been bought and left vacant (Bloomberg, February 27, 2019).
} 
rising trend, there is substantial heterogeneity across regions ( $\mathrm{Wu}$, Gyourko, and Deng, 2016), and prices in ghost towns have fluctuated significantly. ${ }^{11}$ Liu and Xiong (2018) discuss the link between ghost towns and China's massive urbanization process. Woodworth and Wallace (2017) document some stylized facts on ghost towns. Zhang, Jia, and Yang (2016) attribute the high vacancy rates in Chinese cities to rising income inequality. Anglin and others (2014) and Wang, Zhang, and Zhou (2019) show that the career concerns of local government officials contribute to the rapid expansion of new urban districts, which subsequently contributed to the emergence of potential ghost towns. For tractability and given the focus of our paper, we abstract from these differences across the housing markets in different regions; as such, our paper can be interpreted as mainly capturing the housing market dynamics in major Chinese cities, although the main conclusions (e.g., financial market incompleteness makes housing speculation more likely, all else being equal) still apply to smaller cities.

The fourth strand of literature focuses on China's financial system. Some studies (e.g., Lardy, 2008) believe that widespread financial repression (per the definition of McKinnon, 1973 and Shaw, 1973) exists in China. According to these studies, interest rates are artificially capped so that the government can fund its (explicit or implicit) debts at lower interest rates, which in turn supports government-led growth. Allen, Qian, and $\mathrm{Gu}$ (2017) hold a related view, although they highlight the distinction between formal financial sectors (stock market and banking sector) and "alternative financial sectors" operating largely outside the markets and formal institutions. Amstad, Sun, and Xiong (forthcoming) provide an overview of China's financial system and a thorough introduction to the institutional set-up in China. ${ }^{12}$

Our paper contributes to the literature on three fronts. First and foremost, we highlight the role of financial market incompleteness and emphasize the importance of employing "nonhousing policies" to solve the housing problem. This is different from the financial repression view in the sense that the channels in our paper still exist even in the absence of governmentcontrolled interest rates. Second, we provide a tractable DSGE model that can be used to conduct policy experiments; despite the simplicity of our model, it captures key features of the Chinese housing market, and can be used to study both the housing price dynamics and the crowding-out effects on non-housing sectors. Third, we present some stylized facts on Chinese housing and financial markets, including the facts during the COVID-19 crisis.

\section{Motivating Empirical Evidence}

This section presents three stylized facts that motivate our analysis. First, regarding the supply of funds, the household deposits-to-GDP ratio in China has been on a broad rising trend since the housing market reform in 1998. As shown in Figure 3 (where the 2020 ratio is

\footnotetext{
${ }^{11}$ For example, the housing price per square meter in Ordos City dropped from RMB 20,000 to RMB 3,000 ( $Q Q$ News, April 2, 2020).

${ }^{12}$ Separately, Brunnermeier, Sockin, and Xiong (2017) study the macroeconomic implications of China's financial market liberalization, and find that China's current, more liberal financial system poses challenges for the government to experiment with a temporary stimulus that could be reversed easily soon after its inception.
} 
calculated using the stock of deposits in the third quarter and a nominal GDP of RMB 100,000 billion, an official estimate released on October $\left.31,2020^{13}\right)$, it has risen from a little over 60 percent in 1998 to 90 percent in 2020. An important exception occurred in 2007 when the ratio dropped more than 10 percentage points. However, this is most likely due to China's stock market boom in 2007. In fact, there is a clear negative correlation between these two series, which is consistent with the prediction of our model described subsequently.

Figure 3. Household Saving Deposit and Stock Price Index

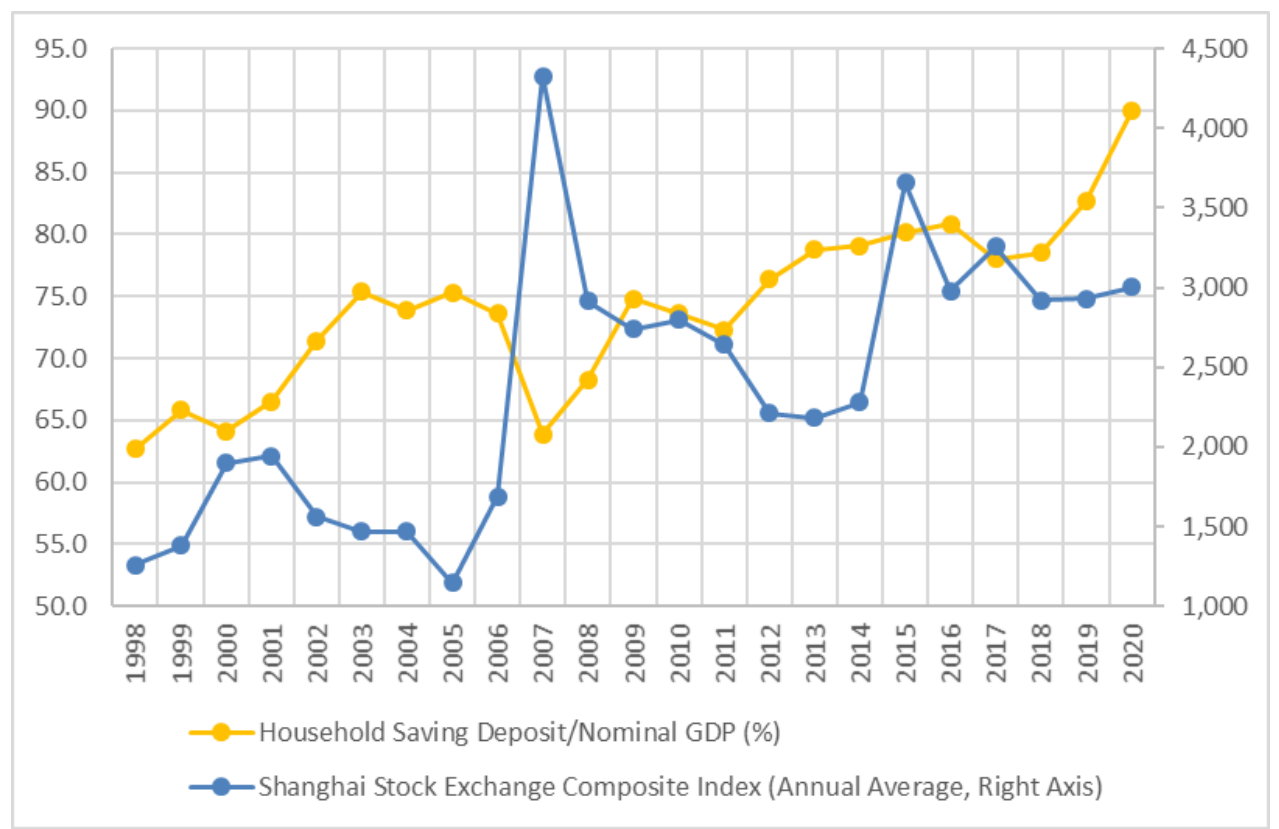

Source: CEIC and author calculations.

Second, regarding households' demand for funds, individuals' residential housing mortgage loan-to-GDP ratio has been on a steady rising trend (Figure 4, red line). The ratio has risen from close to 0 (when the commercial residential market opened in 1998) to more than 30 percent in 2020. Although no such data are available for 2009 and 2010, it is clear that the global financial crisis did not reverse the rising trend.

Third, regarding corporates' demand for funds, the real estate development loan-to-GDP ratio has also been rising, albeit at a slower rate than the mortgage loan-to-GDP ratio (Figure 4 , green line). ${ }^{14}$ This could reflect the limited land supply, which has somewhat restricted the expansion of the real estate development and its mortgage loan demand.

\footnotetext{
${ }^{13}$ The same comment applies to other 2020 data in subsequent figures. The GDP estimate can be found here.

${ }^{14}$ All the numbers presented in Figure 3 and Figure 4 have been cross-checked against numbers published elsewhere.
} 
Figure 4. Real Estate Loan Stock and House Price

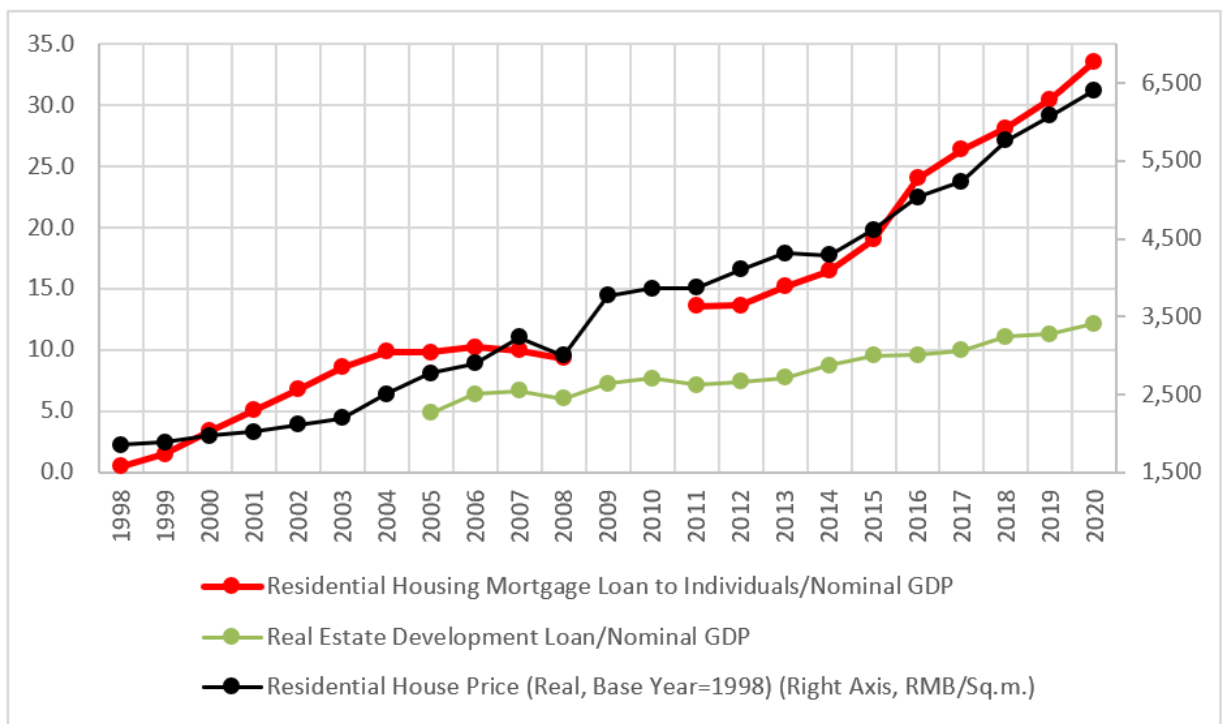

Source: CEIC and author calculations.

\section{Model}

The model is a DSGE model with two types of households: "Poor" households or renters, accounting for $\phi$ fraction of the total population; and "rich" households or housing investors, accounting for $1-\phi$ fraction. It extends the model of Iacoviello (2005) by including: (1) Renters and housing investors; (2) Real estate developers; (3) Financial market incompleteness. Specifically, this section will present the model set-up (including households, real estate developers, and non-real estate producers), the equilibrium, impulse response functions, as well as discussions of the model and results.

\section{A Households}

At period there is a mass $N_{t}$ of infinitely-lived households who can be renters or housing investors. The level of impatience, which is controlled by a discount factor, determines whether a household chooses to be a renter or an investor.

\section{A.1 Renters}

The renters are "poor" households who rent houses to live in rather than to buy and own. They account for $\phi_{t}$ share of the total household population $N_{t}$. $\phi_{t}$ is subjective to shocks, which means a change in the population share between the renters and the investors (described in the next sub- 
section). Each renter inelastically supplies one unit of labor. The renters are homogeneous.

Importantly, these renters are "poor" in the sense that they are unable to afford the down payments for house purchases and thus are unable to access the mortgage finance market that is available to housing investors (as subsequently described). Instead, they can only deposit their surplus funds with banks, which in turn lend to housing investors and real estate developers. Given the paper's focus, banks are assumed to play a passive role of simply passing the renters' deposits to housing investors and real estate developers, so we abstract banks from the model. This simple model captures a key feature of the Chinese financial market, where a large fraction of households effectively only has one saving channel, which is to deposit with banks; and these households are also renting houses. The higher the share $(\phi)$ of these households is, the more incomplete the financial markets are.

The individual renter maximizes the life-time expected utility by choosing consumption $c_{t}^{R}$, housing services $h_{t}^{R}$, and the level of deposits $d_{t}^{R}$, that is:

$$
\max _{c_{t}^{R}, h_{t}^{R}, d_{t}^{R}} \mathbb{E}_{t} \sum_{t=0}^{\infty} \beta_{R, t}^{t} U_{t}^{R}\left(c_{t}^{R}, h_{t}^{R}\right),
$$

subject to the budget constraint:

$$
c_{t}^{R}+p_{t}^{r} h_{t}^{R}+d_{t}^{R}=\left(1+i_{t-1}\right) d_{t-1}^{R}+\frac{Y_{t}}{N_{t}}
$$

In the utility function $(1), \beta_{R, t}$ is the discount factor of the renters, which is subject to shocks (see the impulse response subsection). We assume that renters are more patient than investors (described below) (that is, $\beta_{R, t}>\beta_{I, t}$ ), partly reflecting the reportedly inadequate and unequal social safety nets (poorer households, who are more likely to be renters, tend to have less access to social safety nets). The utility function form will be specified later. In the budget constraint equation (2), $p_{t}^{r}$ is the rental price, $i_{t}$ is the interest rate for deposits, and $\frac{Y_{t}}{N_{t}}$ is the renter's income from non-housing consumption goods production, where $Y_{t}$ is the aggregate output of the nonhousing consumption goods. ${ }^{1}$ As is standard in the literature, all prices are expressed in terms of units of consumption goods.

We now derive the equilibrium conditions for renters. The Lagrangian function can be written

${ }^{1}$ More specifically, as explained later, the $N_{t}$ households as a whole (including all renters and all investors) own the non-housing consumption goods producers and equally split the (off-equilibrium) profit from these producers. Hence, for an individual renter (and an individual investor), the total income from these producers equals $W_{t}+$ $\frac{Y_{t}-W_{t} N_{t}}{N_{t}}=\frac{Y_{t}}{N_{t}}$, where $W_{t}$ is the wage. 
as:

$$
£^{R}=\mathbb{E}_{t} \sum_{t=0}^{\infty}\left[\beta_{R, t}^{t} U_{t}^{R}\left(c_{t}^{R}, h_{t}^{R}\right)+\lambda_{t}^{R}\left(\left(1+i_{t-1}\right) d_{t-1}^{R}+\frac{Y_{t}}{N_{t}}-c_{t}^{R}-p_{t}^{r} h_{t}^{R}-d_{t}^{R}\right)\right]
$$

The first-order condition (FOC) with respect to $c_{t}^{R}$ is:

$$
\begin{aligned}
\lambda_{t}^{R} & =\beta_{R, t}^{t} U_{t, c^{R}}^{R}\left(c_{t}^{R}, h_{t}^{R}\right) \\
\lambda_{t+1}^{R} & =\mathbb{E}_{t}\left[\beta_{R, t}^{t+1} U_{t+1, c^{R}}^{R}\left(c_{t+1}^{R}, h_{t+1}^{R}\right)\right]
\end{aligned}
$$

The FOC with respect to $d_{t}^{R}$ is:

$$
\lambda_{t}^{R}=\lambda_{t+1}^{R}\left(1+i_{t}\right)
$$

Inserting (3) and (4) into (5), we have:

$$
U_{t, c^{R}}^{R}\left(c_{t}^{R}, h_{t}^{R}\right)=\mathbb{E}_{t}\left[\beta_{R, t} U_{t+1, c^{R}}^{R}\left(c_{t+1}^{R}, h_{t+1}^{R}\right)\right]\left(1+i_{t}\right)
$$

Equation (6) is the inter-temporal optimality condition of renters or the Euler equation. The LHS is the marginal benefit of consuming one more unit today, and the RHS is the marginal cost of doing so: This one unit of consumption good could have been saved to generate $\left(1+i_{t}\right)$ units of consumption goods in the next period, and each unit would generate a discounted marginal utility of $\beta_{R, t} U_{t+1, c^{R}}^{R}\left(c_{t+1}^{R}, h_{t+1}^{R}\right)$. The renters would adjust until the two sides are equal.

FOC with respect to $h_{t}^{R}$ is:

$$
\beta_{R, t}^{t} U_{t, h^{R}}^{R}\left(c_{t}^{R}, h_{t}^{R}\right)=\lambda_{t}^{R} p_{t}^{r}
$$

Inserting (3) into (7), we have:

$$
U_{t, h^{R}}^{R}\left(c_{t}^{R}, h_{t}^{R}\right)=p_{t}^{r} U_{t, c^{R}}^{R}\left(c_{t}^{R}, h_{t}^{R}\right)
$$

Equation (8) is the intra-temporal optimality condition of renters. The left-hand-side (LHS) is the marginal benefit (utility gain) of increasing the rental housing by one unit, and the right-hand-side (RHS) is the marginal cost of doing so: It would cost $p_{t}^{r}$ units of consumption goods, and each unit of consumption good has a marginal utility of $U_{t, c^{R}}^{R}\left(c_{t}^{R}, h_{t}^{R}\right)$. In equilibrium, the two sides should be equal.

The two optimality conditions (8) and (6), along with the renter's budget constraint (2), jointly determine $c_{t}^{R}, h_{t}^{R}, d_{t}^{R}$. 


\section{A.2 Investors}

The investors are households who borrow funds and buy houses. They then decide how much housing would be used for their own living, and how much to rent out. The investors take up to $\left(1-\phi_{t}\right)$ share of households total population $N_{t}$, and are homogeneous within this type. Each investor also inelastically supplies one unit of labor, and owns one real estate developer.

The individual investor maximizes the life-time expected utility by choosing consumption $c_{t}^{I}$, housing stock $h_{t}^{I}$ for own living, housing stock $h_{t}^{R I}$ for investment (i.e., rental), and the level of debt $b_{t}^{I}$ :

$$
\max _{c_{t}^{I}, h_{t}^{I}, h_{t}^{R I}, b_{t}^{I}} \mathbb{E}_{t} \sum_{t=0}^{\infty} \beta_{I}^{t} U_{t}^{I}\left(c_{t}^{I}, h_{t}^{I}\right),
$$

subject to the budget constraint:

$$
c_{t}^{I}+p_{t}^{h}\left(h_{t}^{I}+h_{t}^{R I}\right)+\left(1+i_{t-1}\right) b_{t-1}^{I}=p_{t}^{r} h_{t}^{R I}+b_{t}^{I}+p_{t}^{h}(1-\delta)\left(h_{t-1}^{I}+h_{t-1}^{R I}\right)+\frac{Y_{t}}{N_{t}}+\pi_{t},
$$

and the collateral constraint on borrowing:

$$
b_{t}^{I} \leq m_{t} p_{t}^{h}\left(h_{t}^{I}+h_{t}^{R I}\right)
$$

Equation (10) suggests that the total resources available to an individual investor include: A rental income $p_{t}^{r} h_{t}^{R I}$ from renters; external financing $b_{t}^{I}$ from the financial market; the market value of the depreciated house purchased in the last period, $p_{t}^{h}(1-\delta)\left(h_{t-1}^{I}+h_{t-1}^{R I}\right)$, where $\delta$ is the depreciation rate; the individual share of income from goods production $\frac{Y_{t}}{N_{t}}$; and profits $\pi_{t}$ from the real estate developer he owns (explained in Section B in detail). The expenses include: Consumption $c_{t}^{I}$; purchase of new houses $p_{t}^{h}\left(h_{t}^{I}+h_{t}^{R I}\right)$; and repayment of last periods' debt $\left(1+i_{t-1}\right) b_{t-1}^{I}$. The collateral constraint (11) suggests the maximum borrowing cannot exceed a share $m_{t}$ of the house value purchased this period, where $m_{t}$ is the loan-to-value ratio.

Note that the main reason for our collateral constraint assumption is realism: In the mortgage industry practice, the loan amount is determined by the current value of the house rather than the expected value in the next period (as assumed in some literature). An additional benefit of using our set-up is that it somehow circumvents the discussions of how long the maturity of the mortgage loan is, and what "one period" means; by contrast, the suggested alternative set-up will need to involve explaining what " $t+1$ " means in reality.

We now derive the equilibrium conditions for investors. The Lagrangian function can be written 
as:

$$
£^{I}=\mathbb{E}_{t} \sum_{t=0}^{\infty} \beta_{I}^{t}\left[\begin{array}{c}
U_{t}^{I}\left(c_{t}^{I}, h_{t}^{I}\right) \\
+\lambda_{t}^{I}\left(p_{t}^{r} h_{t}^{R I}+b_{t}^{I}+p_{t}^{h}(1-\delta)\left(h_{t-1}^{I}+h_{t-1}^{R I}\right)+\frac{Y_{t}}{N_{t}}+\pi_{t}\right. \\
\left.-c_{t}^{I}-p_{t}^{h}\left(h_{t}^{I}+h_{t}^{R I}\right)-\left(1+i_{t-1}\right) b_{t-1}^{I}\right) \\
+\mu_{t}\left(m_{t} p_{t}^{h}\left(h_{t}^{I}+h_{t}^{R I}\right)-b_{t}^{I}\right)
\end{array}\right]
$$

FOC with respect to $c_{t}^{I}$ is:

$$
\begin{aligned}
\lambda_{t}^{I} & =\beta_{I}^{t} U_{t, c^{I}}^{I}\left(c_{t}^{I}, h_{t}^{I}\right) \\
\lambda_{t+1}^{I} & =\mathbb{E}_{t}\left[\beta_{I}^{t+1} U_{t+1, c^{I}}^{I}\left(c_{t}^{I}, h_{t}^{I}\right)\right]
\end{aligned}
$$

FOC with respect to $h_{t}^{I}$ is:

$$
\beta_{I}^{t} U_{t, h_{t}^{I}}^{I}\left(c_{t}^{I}, h_{t}^{I}\right)-\lambda_{t}^{I} p_{t}^{h}+\beta_{I}^{t} \mu_{t} m_{t} p_{t}^{h}+\lambda_{t+1}^{I} p_{t+1}^{h}(1-\delta)=0
$$

That is,

$$
U_{t, h_{t}^{I}}^{I}\left(c_{t}^{I}, h_{t}^{I}\right)+\mu_{t} m_{t} p_{t}^{h}+\beta_{I} \mathbb{E}_{t}\left[(1-\delta) p_{t+1}^{h} U_{t+1, c^{I}}^{I}\left(c_{t+1}^{I}, h_{t+1}^{I}\right)\right]=U_{t, c^{I}}^{I}\left(c_{t}^{I}, h_{t}^{I}\right) p_{t}^{h}
$$

Equation (15) is the inter-temporal optimality condition of investors. The LHS is the marginal benefits of buying (and living in) one more unit of house, which include three components: It increases the utility by $U_{t, h_{t}^{I}}^{I}\left(c_{t}^{I}, h_{t}^{I}\right)$ from living in the extra unit of house; The larger housing size (and housing value) allows the investor to increase his borrowing by $m_{t} p_{t}^{h}$ units, with each unit of extra borrowing worth $\mu_{t}$ units of utility; And $(1-\delta)$ unit of the house can be passed on to the next period, which is worth $(1-\delta) p_{t+1}^{h}$ units (again in terms of units of consumption goods) or $\beta_{I}(1-\delta) p_{t+1}^{h} U_{t+1, c^{I}}^{I}\left(c_{t+1}^{I}, h_{t+1}^{I}\right)$ utility. The RHS is the marginal cost of doing so: One unit of house costs $p_{t}^{h}$ units of consumption goods or $U_{t, c^{I}}^{I}\left(c_{t}^{I}, h_{t}^{I}\right) p_{t}^{h}$ units of utility. In equilibrium, the two sides should be equal.

FOC with respect to $h_{t}^{R I}$ after plugging in $\lambda_{t}^{I}$ and $\lambda_{t+1}^{I}$ :

$$
U_{t, c^{I}}^{I}\left(c_{t}^{I}, h_{t}^{I}\right) p_{t}^{r}+\mu_{t} m_{t} p_{t}^{h}+\beta_{I} \mathbb{E}_{t}\left[(1-\delta) p_{t+1}^{h} U_{t+1, c^{I}}^{I}\left(c_{t+1}^{I}, h_{t+1}^{I}\right)\right]=U_{t, c^{I}}^{I}\left(c_{t}^{I}, h_{t}^{I}\right) p_{t}^{h}
$$

Equations (15) and (16) imply that

$$
U_{t, c^{I}}^{I}\left(c_{t}^{I}, h_{t}^{I}\right) p_{t}^{r}=U_{t, h_{t}^{I}}^{I}\left(c_{t}^{I}, h_{t}^{I}\right)
$$

Equation (17) is the intra-temporal optimality condition. The LHS is the marginal utility 
gain of renting out one more unit of house - doing so increases the income by $p_{t}^{r}$, amounting to $U_{t, c^{I}}^{I}\left(c_{t}^{I}, h_{t}^{I}\right) p_{t}^{r}$ units of utility. But this would mean reducing the housing size for his own living purpose by one unit, amounting to $U_{t, h_{t}^{I}}^{I}\left(c_{t}^{I}, h_{t}^{I}\right)$ units of utility loss, as captured by the RHS. The investor would adjust so that the two sides are equal in equilibrium.

We also need to solve for the investor's optimal borrowing amount. FOC with respect to $b_{t}^{I}$ is (after plugging in $\lambda_{t}^{I}$ and $\lambda_{t+1}^{I}$ ):

$$
U_{t, c^{I}}^{I}\left(c_{t}^{I}, h_{t}^{I}, n_{t}^{I}\right)=\mu_{t}+\beta_{I} \mathbb{E}_{t}\left[\left(1+i_{t}\right) U_{t+1, c^{I}}^{I}\left(c_{t+1}^{I}, h_{t+1}^{I}, n_{t+1}^{I}\right)\right]
$$

Appendix 1 shows that the investor will always want to borrow up to the limit, that is:

$$
b_{t}^{I}=m_{t} p_{t}^{h}\left(h_{t}^{I}+h_{t}^{R I}\right)
$$

The intuition is as follows. The equilibrium interest rate in steady state needs to satisfy renters' intra-temporal optimality condition $\beta_{R}(1+i)=1$, that is, the steady state interest rate $i=\frac{1}{\beta_{R}}-1$. Since the renters are more patient than the investors $\left(\beta_{R}>\beta_{I}\right)$, this interest rate is lower than the one implied by investors' intra-temporal optimality condition. Hence, investors always find it optimal to borrow as much as possible, which is also consistent with the assumption that they are more impatient than renters.

In sum, we have the three optimality conditions $(15),(16),(18)$, the investor's budget constraint (10), and the binding collateral constraint (19) to determine $c_{t}^{I}, h_{t}^{I}, h_{t}^{R I}, b_{t}^{I}$, and $\mu_{t}$.

\section{B Real Estate Developer}

We now turn to the firm side, which includes the real estate developers and the non-real estate consumption goods producers. For tractability, we assume that each investor is owned by a real estate developer. Each developer borrows $b_{t}^{D e v}$ to hire labor $n_{t}^{D e v}$ and acquire land $l_{t}$, with which to produce new houses. The flow of funds satisfys the following:

$$
b_{t}^{D e v}=W_{t} n_{t}^{D e v}+p_{t}^{l} l_{t}
$$

The production function of new houses is:

$$
y_{t}^{h}=A_{t}\left(n_{t}^{D e v}\right)^{\gamma}\left(l_{t}\right)^{1-\gamma}
$$


This equation implies that the production is realized when the aggregate $\operatorname{TFP} A_{t}$ is realized.

At the next period $t+1$, when the house prices $p_{t+1}^{h}$ are known, the developer receives house sale revenues of $p_{t+1}^{h} y_{t}^{h}$ and needs to repay the debt with interest, amounting to $\left(1+i_{t}\right) b_{t}^{\text {Dev }}$. To ensure that the developer does not default in expectation, we require:

$$
\left(1+i_{t}\right) b_{t}^{D e v} \leq \mathbb{E}_{t}\left[A_{t} p_{t+1}^{h}\left(n_{t}^{D e v}\right)^{\gamma}\left(l_{t}\right)^{1-\gamma}\right]
$$

The developer maximizes the next period's expected profits by choosing $n_{t}^{D e v}, l_{t}$, and $b_{t}^{D e v}$ :

$$
\max _{n_{t}^{D e v}, l_{t}, b_{t}^{D e v}} \mathbb{E}_{t}\left[A_{t} p_{t+1}^{h}\left(n_{t}^{\text {Dev }}\right)^{\gamma}\left(l_{t}\right)^{1-\gamma}-\left(1+i_{t}\right) b_{t}^{\text {Dev }}\right]
$$

We now derive the equilibrium conditions for developers. The Lagrangian function can be written as:

$$
\begin{aligned}
£^{D e v}= & \mathbb{E}_{t}\left[A_{t} p_{t+1}^{h}\left(n_{t}^{D e v}\right)^{\gamma}\left(l_{t}\right)^{1-\gamma}-\left(1+i_{t}\right)\left(W_{t} n_{t}^{D e v}+p_{t}^{l} l_{t}\right)\right]+ \\
& \lambda_{t} \mathbb{E}_{t}\left[A_{t} p_{t+1}^{h}\left(n_{t}^{D e v}\right)^{\gamma}\left(l_{t}\right)^{1-\gamma}-\left(1+i_{t}\right)\left(W_{t} n_{t}^{D e v}+p_{t}^{l} l_{t}\right)\right]
\end{aligned}
$$

where we have replaced $b_{t}^{\text {Dev }}$ using (20).

FOC with respect to the labor demand $n_{t}^{\text {Dev }}$ is:

$$
\begin{aligned}
& \mathbb{E}_{t}\left[\gamma A_{t} p_{t+1}^{h}\left(n_{t}^{D e v}\right)^{\gamma-1}\left(l_{t}\right)^{1-\gamma}-\left(1+i_{t}\right) W_{t}\right]+ \\
& \lambda_{t} \mathbb{E}_{t}\left[\gamma A_{t} p_{t+1}^{h}\left(n_{t}^{D e v}\right)^{\gamma-1}\left(l_{t}\right)^{1-\gamma}-\left(1+i_{t}\right) W_{t}\right] \\
= & 0
\end{aligned}
$$

For the same reason as above, it can be shown that the real estate developer would also borrow up to the limit in equilibrium (note that the developer is owned by the investor, who is more impatient than the renter). Hence, (22) binds and $\lambda_{t}>0$ by the Kuhn-Tucker condition. To ensure that the developer's FOC (24) holds, we have

$$
\mathbb{E}_{t}\left[\gamma A_{t} p_{t+1}^{h}\left(n_{t}^{D e v}\right)^{\gamma-1}\left(l_{t}\right)^{1-\gamma}-\left(1+i_{t}\right) W_{t}\right]=0
$$


Therefore, the developer's optimal labor demand $n_{t}^{\text {Dev }}$ is determined by:

$$
\mathbb{E}_{t}\left[\gamma A_{t} p_{t+1}^{h}\left(n_{t}^{D e v}\right)^{\gamma-1}\left(l_{t}\right)^{1-\gamma}\right]=W_{t}\left(1+i_{t}\right)
$$

Equation (25) is intuitive. The LHS is the marginal benefit of hiring one extra unit of labor: It would increase the house production by $\gamma A_{t}\left(n_{t}^{\text {Dev }}\right)^{\gamma-1}\left(l_{t}\right)^{1-\gamma}$ units, and each unit of house is worth $p_{t+1}^{h}$ at $t+1$. The RHS is the marginal cost of doing so: The extra unit of labor costs $W_{t}$, which is borrowed at time $t$ and would grow to $W_{t}\left(1+i_{t}\right)$ at time $t+1$. The two sides would equal in equilibrium.

Similarly, we can derive the land demand function $l_{t}$ as:

$$
\mathbb{E}_{t}\left[(1-\gamma) A_{t} p_{t+1}^{h}\left(n_{t}^{D e v}\right)^{\gamma}\left(l_{t}\right)^{-\gamma}\right]=p_{t}^{l}\left(1+i_{t}\right)
$$

Inserting $W_{t}$ and $p_{t}^{l}$ from (25) and (26) into (20), we have:

$$
\begin{aligned}
b_{t}^{\text {Dev }} & =\frac{\mathbb{E}_{t}\left[\gamma A_{t} p_{t+1}^{h}\left(n_{t}^{\text {Dev }}\right)^{\gamma-1}\left(l_{t}\right)^{1-\gamma}\right]}{1+i_{t}} n_{t}^{\text {Dev }}+\frac{\mathbb{E}_{t}\left[(1-\gamma) A_{t} p_{t+1}^{h}\left(n_{t}^{\text {Dev }}\right)^{\gamma}\left(l_{t}\right)^{-\gamma}\right]}{1+i_{t}} l_{t} \\
& =\frac{\mathbb{E}_{t}\left[A_{t} p_{t+1}^{h}\left(n_{t}^{\text {Dev }}\right)^{\gamma}\left(l_{t}\right)^{1-\gamma}\right]}{1+i_{t}}
\end{aligned}
$$

Hence:

$$
b_{t}^{\text {Dev }}\left(1+i_{t}\right)=\mathbb{E}_{t}\left[A_{t} p_{t+1}^{h}\left(n_{t}^{D e v}\right)^{\gamma}\left(l_{t}\right)^{1-\gamma}\right]
$$

This verifies that the developer's collateral constraint binds. Moreover, the profit function implies that the developer earns a zero profit ex ante, that is, in expectation. Ex post, the realized profit of the developer can be non-zero and is given by:

$$
\pi_{t+1}=A_{t} p_{t+1}^{h}\left(n_{t}^{D e v}\right)^{\gamma}\left(l_{t}\right)^{1-\gamma}-b_{t}^{D e v}\left(1+i_{t}\right)
$$

Since the investor owns the developer, the realized profits of the developer $\pi_{t+1}$ would become one revenue of the investor, as reflected in the investor's budget constraint. 


\section{Production of Non-housing Consumption Goods}

We assume that the sector of non-housing consumption goods is perfectly competitive. Denote the aggregate non-housing consumption goods production by $Y_{t}$. For tractability, we assume that its production function uses labor as the only input and takes the following form:

$$
Y_{t}=A_{t}\left(N_{t}^{G}\right)^{\alpha}
$$

where $N_{t}^{G}$ is the aggregate labor hired by the non-housing consumption goods industry.

Note that for simplicity, we do not allow the non-housing sector to borrow. This assumption is not central to our main results because the housing sector can still interact with (crowd out) the non-housing sector through the labor channel. Moreover, it is well-understood that real estate development and house purchases are more interest-sensitive and involve more borrowing than most non-housing sectors. Finally, if we do allow the non-housing sector to borrow and model the banking sector separately, we would also need to assume that banks expect housing prices to appreciate. As a result, real estate loans are expected to have a lower default risk than non-housing loans, and banks will lend more to the housing sector than the non-housing sector (consistent with the empirical evidence). Therefore, our simplifying assumption can be understood as normalizing the non-housing sector's borrowing to zero and capturing the difference between the housing and non-housing's borrowings.

The aggregate profit function is given by

$$
A_{t}\left(N_{t}^{G}\right)^{\alpha}-W_{t} N_{t}^{G}
$$

The (off-equilibrium) profit is evenly distributed to the entire household sector, including each renter and each investor. In equilibrium, the aggregate $N_{t}^{G}$ chosen by the industry will be such that the aggregate profit is zero, which implies that

$$
W_{t}=A_{t} \alpha\left(N_{t}^{G}\right)^{\alpha-1}
$$

This implicitly defines the labor demand function by the non-housing consumption goods industry. 


\section{Market Clearing Conditions}

In equilirium, all markets clear. Specifically:

Housing market clearing:

$$
\left[\left(1-\phi_{t}\right) N_{t} h_{t}^{I}+\left(1-\phi_{t}\right) N_{t} h_{t}^{R I}\right]-(1-\delta)\left[\left(1-\phi_{t-1}\right) N_{t-1} h_{t-1}^{I}+\left(1-\phi_{t-1}\right) N_{t-1} h_{t-1}^{R I}\right]=\left(1-\phi_{t}\right) N_{t} y_{t}^{h}
$$

The LHS is the total housing demand, where the two terms in the first brackets are the total housing stock demanded by investors in period $t$ for both living and rental purposes; the two terms in the second brackets are that in period $t-1$, after accounting for depreciation. The RHS is the total housing supply in period $t$. This condition determines the house price $p_{t}^{h}$.

Rental market clearing:

$$
\phi_{t} N_{t} h_{t}^{R}=\left(1-\phi_{t}\right) N_{t} h_{t}^{R I}
$$

The LHS is the total rental demand by renters, and the RHS is the total rental supply by investors. This condition determines the rental rate $p_{t}^{r}$.

Bond market clearing:

$$
\left(1-\phi_{t}\right) N_{t} b_{t}^{D e v}+\left(1-\phi_{t}\right) N_{t} b_{t}^{I}=\phi_{t} N_{t} d_{t}^{R}
$$

The LHS consists of the total bond demand by real estate developers and that by housing investors, respectively. The RHS is the total bond supply by renters. This condition determines the interest rate $i_{t}$.

Labor market clearing:

$$
N_{t}^{G}+\left(1-\phi_{t}\right) N_{t} n_{t}^{D e v}=N_{t}
$$

The LHS consists of the total labor demand by non-housing consumption goods producers and that by real estate developers, respectively. The RHS is the total labor supply. This condition determines the wage $W_{t}$.

Land market clearing:

$$
\left(1-\phi_{t}\right) N_{t} l_{t}=\bar{L}
$$

The LHS is the land demand by real estate developers in period $t$, and the RHS is the land supply. To reflect the fact that the land supply in China is subject to a strict rationing by local governments (partly in an effort to maintain a high land price and high fiscal revenue), we assume that the land supply (i.e., the flow) in each period is the same $(\bar{L})$, which implies that the total land stock still increases over time (at a constant rate). This condition determines the land price $p_{t}^{l}$. 


\section{E Summary}

This subsection summarizes the lists of endogenous and exogenous variables, specifies the utility functional forms, and discusses the calibration of key parameters.

The key equilibrium objects (endogenous variables) $c^{R}, h^{R}, d^{R}, c^{I}, h^{I}, h^{R I}, b^{I}, \mu, b^{D e v}, y^{h}, n^{D e v}, l$,

$Y, N^{G}, p^{h}, p^{r}, i, W, p^{l}$ are determined by equations (2), (8), (6), (10), (15), (16), (18), (19), (20), (21), (25), (26), (29), (30), (31), (32), (33), (34), and (35). In addition, Appendix 2 lists the complete system of equations to solve for the steady state.

The exogenous variables are as follows. In principle, shocks can occur in any of these variables. For the purpose of our research questions, we chose to shock the renter population share and renter discount factor.

\begin{tabular}{c|l}
\hline Exogenous variable & \multicolumn{1}{c}{ Description } \\
\hline \hline$N$ & Total population of households \\
\hline$m$ & Loan-to-value ratio \\
\hline$A$ & TFP \\
\hline$\phi$ & Renter population share \\
\hline$\beta_{R}$ & Renter discount factor \\
\hline
\end{tabular}

We choose the functional forms for utility functions a la Iacoviello (2005):

$$
\begin{aligned}
U_{t}^{R}\left(c_{t}^{R}, h_{t}^{R}\right) & =\ln c_{t}^{R}+j \ln h_{t}^{R} \\
U_{t}^{I}\left(c_{t}^{I}, h_{t}^{I}\right) & =\ln c_{t}^{I}+\kappa \ln h_{t}^{I}
\end{aligned}
$$

Therefore:

$$
\begin{aligned}
U_{t, c^{R}}^{R}\left(c_{t}^{R}, h_{t}^{R}\right) & =\frac{1}{c_{t}^{R}} \\
U_{t, h^{R}}^{R}\left(c_{t}^{R}, h_{t}^{R}\right) & =\frac{j}{h_{t}^{R}} \\
U_{t, c^{I}}^{I}\left(c_{t}^{I}, h_{t}^{I}\right) & =\frac{1}{c_{t}^{I}} \\
U_{t, h^{I}}^{I}\left(c_{t}^{I}, h_{t}^{I}\right) & =\frac{\kappa}{h_{t}^{I}}
\end{aligned}
$$


Finally, the parameters in the model are calibrated based on Chinese data (when available) to capture China-specific features, or the literature (when Chinese data are not available). For example, the share of renters in households population is estimated as 1 minus the average homeownership ratio by Chinese urban residents ( 74.5 percent), which is the average of the fifth census value in 2000 (74.1 percent) and the sixth census value in 2011 (74.9 percent). In addition, we estimate the share of labor in housing production by manually collecting the data from five large real estate developers in China. Note that the land supply parameter is set to 1 following the assumption discussed above. Details for the calibration of other parameters are provided in Appendix 3, and specific parameter values are as follows:

\begin{tabular}{c|l|c}
\hline Parameter & \multicolumn{1}{|c}{ Description } & Value \\
\hline \hline$\phi_{s s}$ & Share of renters in households population & 0.255 \\
\hline$\beta_{R, s s}$ & Discount factor of the renters & 0.976 \\
\hline$\beta_{I}$ & Discount factor of the investors & 0.85 \\
\hline$\delta$ & Depreciation rate of houses & 0.025 \\
\hline$\gamma$ & Share of labor in housing production & 0.0574 \\
\hline$\alpha$ & Share of labor in goods production & $\frac{2}{3}$ \\
\hline$L$ & Constant supply of new land & 1 \\
\hline$j$ & Weight on housing services by renters & 0.06 \\
\hline$\kappa$ & Weight on housing services by investors & 0.12 \\
\hline
\end{tabular}

\section{F Impulse Responses}

Figure 5 presents the impulse responses of key indicators following a temporary positive shock to $\phi$, which is the share of renters and proxies for the financial market incompleteness. Specifically, the share of renters increases by 1 percentage point at time 0 , and gradually decreases to the original level over time. As discussed in the renter section of the model, this shock corresponds to a scenario where financial markets become more incomplete - suddenly a larger share of households can only save through bank deposits.

The first notable result is the impact on housing price. As shown in the figure, such a shock immediately raises the aggregate deposit, which lowers the interest rate. In turn, this affects both the demand and supply sides in the housing market: The lower interest rate stimulates higher (mortgage) borrowings and higher housing demand by housing investors; It also encourages real estate developers to borrow more funds and produce more new houses. In equilibrium, the demandside effect dominates the supply-side effect (mostly due to the assumption of a rationed land supply in each period), pushing up the equilibrium housing price. Again, the key to understanding this 
result is that "renters" in the model (i.e., people who cannot afford to buy houses) are also people who can only save in terms of bank deposits. In this sense, a higher share of renters also means a higher degree of financial market incompleteness and a larger amount of aggregate deposit.

This result also implies that even though the number of people who can afford buying houses is smaller (because a larger fraction of the population is now renters), each person who can afford now buys larger or multiple houses because the lower interest rate makes it cheaper to buy houses. Indeed, following a decrease in interest rate, it is likely to induce the wealthy people (who have the financial means to afford the down payments of multiple houses) to take another mortgage loan and buy another house for investment/speculation purposes. Therefore, a more incomplete financial market (where a larger share of the population can only save in bank deposits) may lead to a more concentrated homeownership structure and worsen the wealth inequality. This is consistent with anecdotal evidence that it is not uncommon for very rich people to own more than five houses in China.

The second notable result is the crowding-out effect on non-housing sectors. As the real estate developers borrow more, they hire more labor (and land), which increases the wage, decreases the labor available to non-housing sectors, and lowers the production of non-housing consumption goods. This is the case even though the model does not include land as a production factor by non-housing producers. If we account for this additional channel, the crowding-out effect would be even stronger.

In terms of the dynamic effects, it is worth mentioning that there are two countervailing effects from time 1 onwards: First, there is an effect through the extensive margin, where a smaller number of renters/savers tends to decrease the aggregate deposit and increase the interest rate (recall that after the initial increase at time 0 , the fraction of renters $\phi$ decreases from time 1 onwards). Second, there is an effect through the intensive margin, where the higher interest rate at time $t$ induces a higher aggregate deposit at time $t+1$ (via Equation 2), which in turn decreases the interest rate at time $t+1$. The impulse response of the aggregate deposit in Figure 5 indicates that the extensive margin dominates at time 1 (hence a lower-than-steady-state deposit and a higher-than-steadystate interest rate at time 1), and that the intensive margin dominates from time 2 onwards (hence the decrease in deposit and the increase in interest rate at time 1 gradually fade out from time 2 onwards). The dynamics of other variables can be derived accordingly. For example, as the interest rate decreases, the borrowing by a single investor increases. In addition, since this is a one-time temporary shock, all indicators return to their initial steady-state levels over time. If the shock is permanent (i.e., the financial markets become permanently more incomplete), then the impacts would be similar to those observed at time 0 in the temporary shock scenario, as discussed above. 
Figure 5. Impulse Response Functions with A More Incomplete Financial Market
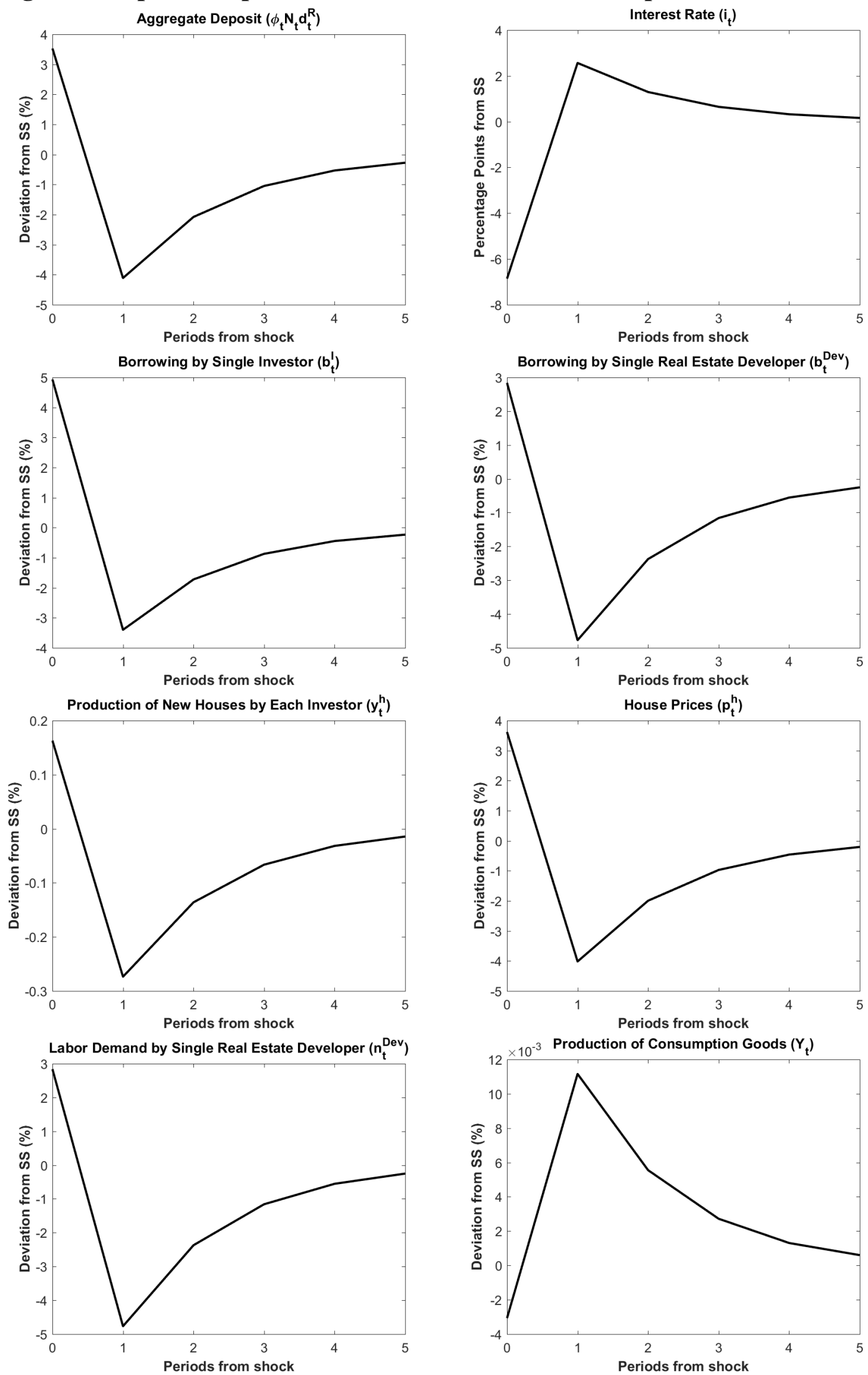

Sources: Author calculations. 
We have also analyzed the impacts of an increase in renters' discount factor. A higher discount factor captures the higher saving propensity of renters, which is in turn driven by China's demographic changes (induced by the one-child policy), the transformation of the social safety net and job security, the (reportedly) expensive higher education, the housing market commercialization reform, etc. This high-saving phenomenon in China is well-documented, such as in Zhang and others (2018). The impulse responses are very similar to those following a higher level of financial market incompleteness: The higher saving propensity associated with the higher discount factor increases aggregate deposit and decreases interest rate. The lower interest rate then sets off the same chain reactions as above: Higher borrowing demand and housing demand by housing investors; Higher borrowing demand and more housing production by real estate developers; Higher housing price and larger crowding-out effects on non-housing sectors.

\section{Conclusion and Policy Implications}

Motivated by several puzzles about the Chinese economy and its housing market, we first present three stylized facts about China's financial markets. Then we highlight the impact of a "slowmoving" structural vulnerability — financial market incompleteness — on China's housing prices in a DSGE model, through both housing demand and supply channels. We find that the high degree of financial market incompleteness in China has played an important role in pushing up the housing price, crowding out the non-housing sectors, and possibly worsening the wealth inequality by making it cheaper for the very rich to engage in housing speculation.

One main policy message from our analysis is that an integrated, comprehensive policy package is needed to tackle the issue of rising housing prices in China. There are two approaches to depress the housing demand and contain the housing price: First, to directly "block" the fund inflow to the housing market, which is effectively the main channel how the macroprudential policies (limits on loan-to-value ratio, debt-to-income ratio, etc.) work to depress housing demand/price; Second, to open up new "outlets" for the funds (via financial market reforms), divert funds away from real estate, and thus indirectly depress housing demand/price. Our paper highlights that the second approach can well complement the first one, and may be needed to help eradicate the root causes of the high housing price. Moreover, the second approach can also mitigate the resource misallocation problem on the supply side and enhance the efficiency of the overall economy by channeling surplus funds to productive non-housing sectors. This is particularly important in the COVID context because without addressing the structural vulnerability of financial market incom-

pleteness, the higher household saving and the government stimulus packages (e.g., fiscal stimulus measures) may fuel the housing bubble and sow seeds for a future crisis. 
One key element of this financial market reform is to move away from the bank-dominated financial system to a well-regulated multi-layer financial system. This system would consist of banks, well-functioning bond markets and multi-layer stock markets, which in turn include the main-board, second-board, and small-and-medium-board stock markets. Such a market would be able to accommodate a rich spectrum of risk preferences and solve the severe risk mismatch problem between the fund supply side and the demand side, that is: the fund supply side — banks_-are relatively risk-averse but are dominating the financial system; and the fund demand side consists of firms with a full spectrum of risks, ranging from mature firms with low risks to start-ups with high risks. The following measures proposed in IMF (2019) are moving towards this direction: Targeting some required reserve ratio cuts for lending to micro and small enterprises (MSEs); and increasing lending to MSEs by 30 percent, and private enterprises receive at least 50 percent of new loans. Our paper's policy recommendation complements these measures and suggests room for extending similar measures to the non-banking financial markets.

Note that our policy recommendation does not contradict the view of Rajan (2006) that investment managers (e.g., private equity managers) have greater incentive to take risks and are more likely to herd with each other than banks. This is because our proposal is to build a mechanism that grants corporates and households the rights to match with each other freely based on their risk profiles/preferences, but this does not mean less regulation. In fact, the government can and should closely monitor this matching mechanism/multi-layer capital market to mitigate financial frauds (especially in the P2P market) and excess risk-taking by adopting the market-friendly policies proposed by Rajan (2006) (e.g., urging all managers to invest some fixed portion of their pay in the funds they manage). ${ }^{2}$

Of course, macroprudential policies and financial market reforms alone cannot solve this complex problem. Since some other underlying forces are pushing up China's household savings and aggravating the consequences of incomplete financial markets, it is important to complement macroprudential policies and financial market reforms with structural reforms, such as strengthening the medical insurance system and social security system.

2 Below is one analog that may help better understand our proposal: The current financial system in China is like an "arranged marriage" where corporates with dramatically different risk profiles are forced to "marry" the dominant and risk-averse banks; by contrast, what we propose is similar to "free marriage" where "men" (a variety of financial institutions, including banks and nonbanks) and "women" (corporates) can freely match with each other based on their risk profiles/preferences. But to ensure the fairness and efficiency of this "free marriage market", some strict rules have to be put in place. And the current issue of emerging fake P2P platforms in China is just like disclosing false information on a dating site. 


\section{Appendix 1: Proof of Investors' Binding Borrowing Constraint}

PROOF:

Use the Kuhn-Tucker condition to check whether the collateral constraint is binding. We have

$$
\mu_{t}\left[m_{t} p_{t}^{h}\left(h_{t}^{I}+h_{t}^{R I}\right)-b_{t}^{I}\right]=0
$$

If (11) is not binding, then $\mu_{t}=0$. We can write the investor's FOC Equation (18) as:

$$
U_{t, c^{I}}^{I}\left(c_{t}^{I}, h_{t}^{I}, n_{t}^{I}\right)=\beta_{I} \mathbb{E}_{t}\left[\left(1+i_{t}\right) U_{t+1, c^{I}}^{I}\left(c_{t+1}^{I}, h_{t+1}^{I}, n_{t+1}^{I}\right)\right]
$$

At steady state, we have

$$
\beta_{I}(1+i)=1
$$

However from (6), we know $\beta_{R}(1+i)=1$ at steady state. With parameter restrictions that $\beta_{R}>\beta_{I}$, therefore $\beta_{I}(1+i)<1$, contradiction. Therefore we cannot have $\mu_{t}=0$. Therefore, $\mu_{t}>0$, and thus we have $b_{t}^{I}=m_{t} p_{t}^{h}\left(h_{t}^{I}+h_{t}^{R I}\right)$.

Q.E.D.

\section{Appendix 2: System of Steady-State Conditions}

This appendix lays out the system of equilibrium conditions in steady state.

$$
\begin{gathered}
c^{R}+p^{r} h^{R}=\frac{Y}{N}+i d^{R} \\
U_{h^{R}}^{R}\left(c^{R}, h^{R}\right)=p_{t}^{r} U_{c^{R}}^{R}\left(c^{R}, h^{R}\right) \\
U_{n^{R}}^{R}\left(c^{R}, h^{R}\right)=-W U_{c^{R}}^{R}\left(c^{R}, h^{R}\right) \\
1=\beta_{R}(1+i) \\
c^{I}+p^{h} \delta\left(h^{I}+h^{R I}\right)+i b_{t}^{I}=\frac{Y}{N}+I+p^{r} h^{R I} \\
{\left[1-\beta_{I}(1-\delta)\right] U_{c^{I}}^{I}\left(c^{I}, h^{I}\right) p^{h}=U_{h^{I}}^{I}\left(c^{I}, h^{I}\right)+\mu m p^{h}} \\
{\left[1-\beta_{I}(1-\delta)\right] U_{c^{I}}^{I}\left(c^{I}, h^{I}\right) p^{h}=U_{c^{I}}^{I}\left(c^{I}, h^{I}\right) p^{r}+\mu m p^{h}} \\
{\left[1-\beta_{I}(1+i)\right] U_{c^{I}}^{I}\left(c^{I}, h^{I}\right)=\mu} \\
b^{I}=m p^{h} h^{I}
\end{gathered}
$$




$$
\begin{gathered}
b^{D e v}=W n^{D e v}+p^{l} l \\
Y^{h}=A\left(n^{D e v}\right)^{\gamma}(l)^{1-\gamma} \\
W=\frac{\gamma A p^{h}\left(n^{D e v}\right)^{\gamma-1}(l)^{1-\gamma}}{1+i} \\
p^{l}=\frac{(1-\gamma) A p^{h}\left(n^{D e v}\right)^{\gamma}(l)^{-\gamma}}{1+i} \\
Y=A\left(N^{G}\right)^{\alpha} \\
W=A \alpha\left(N^{G}\right)^{\alpha-1} \\
\delta\left(h^{I}+h^{R I}\right)=y^{h} \\
(1-\phi) h^{R I}=\phi h^{R} \\
(1-\phi) b^{D e v}+(1-\phi) b^{I}=\phi d^{R} \\
N^{G}+(1-\phi) N n^{D e v}=N \\
(1-\phi) N l=\bar{L}
\end{gathered}
$$

\section{Appendix 3: Parameter Calibration}

The discount factor of the renters $\left(\beta_{R, s s}\right)$ is calibrated by matching the steady-state interest rate to the average deposit rate in China. To proxy for the steady-state level, we use the average one-year benchmark deposit rate in China from 2000 to 2018 (from People's Bank of China), which equals 2.42 percent.

The weight on housing services by renters $(j)$ and weight on housing services by investors $(\kappa)$ are chosen to match another steady-state object, which is the housing GDP as a share of the total GDP. That is, we set the following expression to the average value-added of housing to GDP ratio in China from 2000 to 2018 in the data (from China Statistical Yearbooks in these years):

$$
\frac{\left(1-\phi_{s s}\right) N y_{s s}^{h} p_{s s}^{h}+\phi_{s s} N h^{R} p^{R}}{\left(1-\phi_{s s}\right) N y_{s s}^{h} p_{s s}^{h}+\phi_{s s} N h^{R} p^{R}+Y_{s s}}=0.05
$$

where $\phi_{s s}$ is the share of renters in households population and equals 0.255 , as discussed in the main text; $\left(1-\phi_{s s}\right) N y_{s s}^{h} p_{s s}^{h}$ is the housing value-added produced by real estate developers (due to the one-to-one mapping between real estate developers and housing investors, this also equals 
the market value of houses purchased by housing investors); $\phi_{s S} N h^{R} p^{R}$ is the housing value-added consumed by renters; $Y_{s s}$ is the steady-state output of non-housing production. $y_{s s}^{h}, p_{s s}^{h}, h^{R}, p^{R}, Y_{s S}$ are all general equilibrium objects that depend on both $j$ and $\kappa$.

The share of labor in housing production $(\gamma)$ is calibrated to match the average share of labor costin the total cost of real estate developers. There is no official data on this share. Therefore, we manually calculate it for each of the five large real estate developers in China from 2010 to 2019, including China Overseas Land and Investment, China Vanke, China Evergrande Group, Country Garden, and Sunac China Holdings. In each year, we take the weighted average of the labor cost shares (across the five companies) as the share for the whole industry. We then calibrate/estimate $\gamma$ as the average share across all available years (2010-2019), which equals 5.74 percent.

Finally, the depreciation rate of houses $(\delta)$ takes the standard value from Iacoviello (2005). The discount factor of the investors $\left(\beta_{I}\right)$ and share of labor in goods production $(\alpha)$ take values from Gete (2020), which also studies the housing market and also assumes that the non-housing sector uses labor as the only input. 


\section{References}

[1] Allen, Franklin, Jun Qian, and Xian Gu, 2017, “An Overview of China's Financial System," Annual Review of Financial Economics, ISSN: 1941-1375.

[2] Amstad, Marlene, Guofeng Sun, and Wei Xiong, Forthcoming, The Handbook of China's Financial System.

[3] Anglin, Paul M., David Dale-Johnson, Yanmin Gao, and Guozhong Zhu, 2014, "Patterns of Growth in Chinese Cities: Implications of the Land Lease," Journal of Urban Economics, 83: 87-107.

[4] Arrow, Kenneth, 1964, "The Role of Securities in the Optimal Allocation of Risk Bearing," Review of Economic Studies, 31 (2): 91-96.

[5] Bai, Chong-En, Chang-Tai Hsieh, and Zheng (Michael) Song, 2016. "The Long Shadow of China's Fiscal Expansion," Brookings Papers in Economic Activity.

[6] Bai, Chong-En and Yingyi Qian, 2010, "Infrastructure Development in China: The Cases of Electricity, Highways, and Railways," Journal of Comparative Economics, 38, 34-51.

[7] Brunnermeier, Markus, Michael Sockin, and Wei Xiong, 2017, “China’s Gradualistic Economic Approach and Financial Markets," American Economic Review Papers \& Proceedings, 107 (5): 608-613.

[8] Chen, Zhuo, Zhiguo He, and Chun Liu, 2020, "The Financing of Local Government in China: Stimulus Loan Wanes and Shadow Banking Waxes," Journal of Financial Economics, 137 (1): 42-71.

[9] Chen, Ting, Laura Xiaolei Liu, Wei Xiong, and Li-An Zhou, 2017, "Real Estate Boom and Misallocation of Capital in China," Working Paper.

[10] Chen, Kaiji, Jue Ren, and Tao Zha, 2018, "The Nexus of Monetary Policy and Shadow Banking in China," American Economic Review, 108 (12): 3891-3936.

[11] Chen, Kaiji, and Yi Wen, 2017, “The Great Housing Boom of China," American Economic Journal: Macroeconomics, 9 (2): 73-114.

[12] Du, Zaichao, and Lin Zhang, 2015, "Home-Purchase Restriction, Property Tax and Housing Price in China: A Counterfactual Analysis," Journal of Econometrics, 188 (2): 558-568.

[13] Gan, Li, Feng Li, Xiaomeng Lu, Bofu Deng, Jiandong Luo, Hongyang Wang, Tao Jiang, Liangyan Guo, Sitong Chen, and Xiang Wang, 2016, "Assessment Report on Chinese Household Finance Portfolio Risks," Neo Capital Report.

[14] Gao, Huina, Zhi Liu, and Yue Long, 2019, "Residential Land Supply and Housing Prices in China: An Empirical Analysis of Large Cities," Chapter 15, by Rebecca Chiu, Zhi Liu, and Bertrand Renaud (ed.), International Housing Market Experience and Implications for China. 
[15] Gete, Pedro, 2020, "Expectations and the Housing Boom and Bust: An Open Economy View," Journal of Housing Economics, 49, September.

[16] Glaeser, Edward, Wei Huang, Yueran Ma, and Andrei Shleifer, 2017, "A Real Estate Boom with Chinese Characteristics," Journal of Economic Perspectives, 31(1): 93-116.

[17] Liu, Chang, and Wei Xiong, 2018, “China’s Real Estate Market," NBER Working Paper \#25297.

[18] McKinnon, Ronald I., 1973, Money and Capital in Economic Development, Washington, D.C.: Brookings Institution.

[19] Mei, Dongzhou, Xiaoyong Cui, and Yu Wu, 2018, "House Price Fluctuation, Land Finance and Business Cycle in China," (in Chinese) Economic Research Journal, 1: 35-49.

[20] Minetti, Raoul,Tao Peng, and Tao Jiang, 2019, "Keeping Up with the Zhangs and House Price Dynamics in China," Journal of Economic Dynamics and Control, 109.

[21] He, Hui, Huang, Feng, Liu, Zheng, and Dongming Zhu, 2018, "Breaking the 'Iron Rice Bowl:' Evidence of Precautionary Savings from the Chinese State-Owned Enterprises Reform," Journal of Monetary Economics, 94: 94-113.

[22] He, Hui, Lei Ning, and Dongming Zhu, 2019, “The Impact of Rapid Ageing and Pension Reform on Savings and the Labor Supply: The Case of China,” IMF Working Paper 19/61.

[23] Huang, Yukon, 2017, "Cracking the China Conundrum: Why Conventional Economic Wisdom Is Wrong," Oxford University Press.

[24] Iacoviello, Matteo, 2005, "House Prices, Borrowing Constraints, and Monetary Policy in the Business Cycle," American Economic Review, 95 (3): 739-764.

[25] International Monetary Fund, 2019, People's Republic of China: 2019 Article IV Consultation Staff Report, IMF Country Report No. 19/266.

[26] Rajan, Raghuram G., 2006, "Has Finance Made the World Riskier?" European Financial Management, 12(4): 499-533.

[27] Rungskunroch, Panrawee, Yuwen Yang, and Sakdirat Kaewunruen, 2020, "Does High-Speed Rail Influence Urban Dynamics and Land Pricing?” Sustainability, 12 (7).

[28] Shaw, Edward S., 1973, Financial Deepening in Economic Development, New York: Oxford University Press.

[29] Shepard, Wade, 2015, Ghost Cities of China: The Story of Cities without People in the World's Most Populated Country. London: Zed Books.

[30] Shi, Yu, 2018, "Sectoral Booms and Misallocation of Managerial Talent: Evidence from the Chinese Real Estate Boom,” IMF Working Paper 18/221.

[31] Wang, Zhi, Qinghua Zhang, and Li-An Zhou, 2019, "Career Incentives of City Leaders and Urban Spatial Expansion in China," Review of Economics and Statistics, August. 
[32] Woodworth, Max D., and Jeremy L. Wallace, 2017, “Seeing Ghosts: Parsing China's 'Ghost City' Controversy," Urban Geography, 38(8): 1270-1281.

[33] Wu, Jing, Joseph Gyourko, and Yongheng Deng, 2016, "Evaluating the Risk of Chinese Housing Markets: What We Know and What We Need to Know," China Economic Review, 39: 91-114.

[34] Xiong, Wei, 2019, “The Mandarin Model of Growth," Princeton University Working Paper.

[35] Yang, Zan, Ying Fan, and Liqing Zhao, 2018, "A Reexamination of Housing Price and Household Consumption in China: The Dual Role of Housing Consumption and Housing Investment," Journal of Real Estate Finance and Economics, 56: 472-499.

[36] Zhang, Longmei, Ray Brooks, Ding Ding, Haiyan Ding, Hui He, Jing Lu, and Rui C. Mano, 2018, “China’s High Savings: Drivers, Prospects, and Policies,” IMF Working Paper 18/277.

[37] Zhang, Chuanchuan, Shen Jia, Rudai Yang, 2016, "Housing Affordability and Housing Vacancy in China: The Role of Income Inequality," Journal of Housing Economics, 33: 4-14.

[38] Zhao, Yunhui, 2020, "US Housing Market during COVID-19: Aggregate and Distributional Evidence," COVID Economics, 50 (September): 113-154. 